Note

\title{
Rapid differentiation between short-chain-length and medium-chain-length polyhydroxyalkanoate-accumulating bacteria with spectrofluorometry
}

\author{
Hsan-Au Wu ${ }^{\mathrm{a}}$, Der-Shyan Sheu ${ }^{\mathrm{b}}$, Chia-Yin Lee ${ }^{\mathrm{b}, *}$ \\ a Department of Agricultural Chemistry, National Taiwan University, 1, Sec. 4, Roosevelt Rd., Taipei 106, Taiwan \\ ${ }^{\mathrm{b}}$ Graduate Institute of Agricultural Chemistry, National Taiwan University, 1, Sec. 4, Roosevelt Rd., Taipei 106, Taiwan
}

Received 29 July 2002; received in revised form 21 October 2002; accepted 24 October 2002

\begin{abstract}
An approach for rapid differentiation between short-chain-length (scl) and medium-chain-length (mcl) polyhydroxyalkanoate (PHA) producers was developed. Polyhydroxyalkanoate-accumulated bacterial cells stained with Nile red were suspended in water and subjected to fluorescence spectroscopy at a fixed excitation wavelength of $488 \mathrm{~nm}$. The scl-PHA-accumulated bacteria revealed a maximum emission wavelength at $590 \mathrm{~nm}$, and for mcl-PHA producers were seen at a wavelength of 575 $\mathrm{nm}$. Combining Nile red staining and fluorescence spectroscopy, the accumulated PHA granules could be rapidly differentiated into scl-PHA and mcl-PHA from the intact cells.
\end{abstract}

(C) 2002 Elsevier Science B.V. All rights reserved.

Keywords: Fluorescence spectroscopy; Nile red; Medium-chain-length; Polyhydroxyalkanoate; Short-chain-length

Polyhydroxyalkanoates (PHAs), a sort of biological polyester (Fig. 1), function as carbon and energy reserves in prokaryotic cells (Anderson and Dawes, 1990); a wide range of bacteria synthesize them when a carbon source is provided in excess and one essential growth nutrient is limited (Ramsay et al., 1990). PHA polyesters have been studied intensively by academia and industry in recent decades. Since their physical characteristics are similar to those of petrochemical polyesters, such as polypropylene, and possess biocompatible and biodegradable features, they

* Corresponding author. Tel.: +886-2-2363-0231 ext. 2816; fax: +886-2-2366-0581.

E-mail address: m477@ccms.ntu.edu.tw (C.-Y. Lee). are considered good candidates for biodegradable plastics. Generally, PHAs are categorized into two groups based on the number of carbon atoms in the monomer units: short-chain-length (scl) PHAs consist of 3-5 carbon atoms, and medium-chain-length $(\mathrm{mcl})$ PHAs consist of 6-14 carbon atoms (Anderson and Dawes, 1990). Short-chain-length PHAs possess higher melting temperatures and are stiffer than those of mcl-PHAs, while mcl-PHAs own properties of an elastomer with poor tensile strength and high extension to breakage (Poirier et al., 1995).

Nile red is an oxazone form of Nile blue A, formed by the spontaneous oxidation of Nile blue $\mathrm{A}$ in aqueous solution or by refluxing Nile blue A with dilute sulfuric acid. It is poorly soluble in water but dissolves in a wide variety of organic solvents, such as 


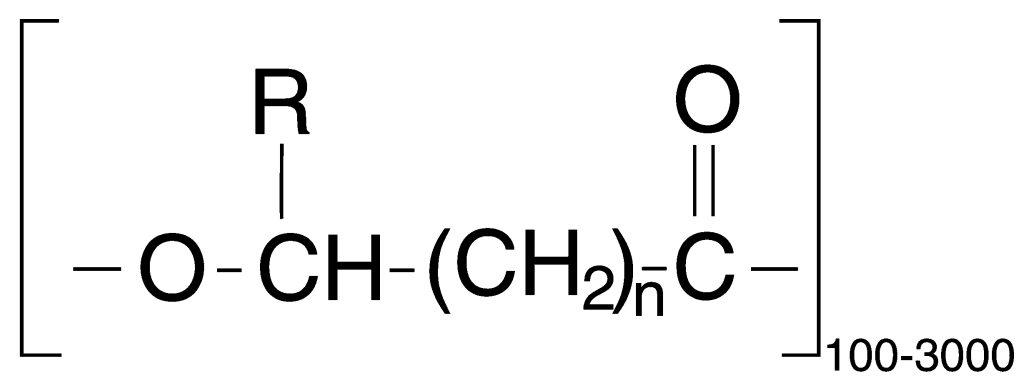

\section{polymer}

$\begin{array}{ll}\mathrm{n}=1 & \mathrm{R}=\text { hydrogen } \\ & \mathrm{R}=\text { methyl } \\ & \mathrm{R}=\text { ethyl } \\ & \mathrm{R}=\text { propyl } \\ & \mathrm{R}=\text { butyl } \\ & \mathrm{R}=\text { pentyl } \\ & \mathrm{R}=\text { hexyl } \\ & \mathrm{R}=\text { heptyl } \\ & \mathrm{R}=\text { octyl } \\ & \mathrm{R}=\text { nonyl } \\ \mathrm{n}=2 & \mathrm{R}=\text { hydrogen } \\ \mathrm{n}=3 & \mathrm{R}=\text { hydrogen }\end{array}$

poly(3-hydroxypropionate)
poly(3-hydroxybutyrate)
poly(3-hydroxyvalerate)
poly(3-hydroxycaproate)
poly(3-hydroxyheptanoate)
poly(3-hydroxyoctanoate)
poly(3-hydroxynonanoate)
poly(3-hydroxydecanoate)
poly(3-hydroxyundecanoate)
poly(3-hydroxydodecanoate)
poly(4-hydroxybutyrate)
poly(5-hydroxyvalerate)

$\mathrm{P}(3 \mathrm{HP})$

$\mathrm{P}(3 \mathrm{HB})$

$\mathrm{P}(3 \mathrm{HV})$

$\mathrm{P}(3 \mathrm{HC})$

$\mathrm{P}(3 \mathrm{HH})$

$\mathrm{P}(3 \mathrm{HO})$

$\mathrm{P}(3 \mathrm{HN})$

$\mathrm{P}(3 \mathrm{HD})$

$\mathrm{P}(3 \mathrm{HUD})$

$\mathrm{P}(3 \mathrm{HDD})$

$\mathrm{P}(4 \mathrm{HB})$

$\mathrm{P}(5 \mathrm{HV})$

Fig. 1. Chemical structure of the polyhydroxyalkanoates produced in bacteria (figure adapted from Poirier et al., 1995).

acetone. The dye is strongly fluorescent in all organic solvents, but is quenched in water (Greenspan et al., 1985). Many methods have been developed for detecting or quantifying intracellular PHA granules based on Nile red staining (Ostle and Holt, 1982; Degelau et al., 1995; Fouchet et al., 1995; Gorenflo et al., 1999; Kranz et al., 1997; Spiekermann et al., 1999). Nonetheless, these methods are not capable of analyzing or differentiating PHA compositions.

In this study, a rapid approach based on Nile red staining was developed for differentiating between scl- and mcl-PHAs from intact cells. Four strains of well-described scl-PHA producers-Ralstonia eutropha H16 ATCC 17699, Comamonas acidovorans ATCC 15668, Pseudomonas glathei ATCC 29195, and Paracoccus versutus (environmental isolated strain), three strains of mcl-PHA producers-Pseudomonas putida ATCC 12633, P. putida GPol [formerly known as Pseudomonas oleovorans GPo1 (van Beilen et al., 2001)] ATCC 29347, and Pseudomonas citro- nellolis ATCC 13674, and two $\mathrm{PHA}^{-}$mutants, $P$. putida GPp104 $\mathrm{PHA}^{-}$and $R$. eutropha $\mathrm{PHB}^{-} 4$ were used for evaluating this approach. Bacteria were cultured in a $250-\mathrm{ml}$ baffled flask containing $50 \mathrm{ml}$ of mineral salt medium (MSM) as a nitrogen limitation condition (Ramsay et al., 1990) and an appropriate carbon source, with a final concentration of $1.5 \%$ gluconate (Sigma) for scl-PHA producers and $\mathrm{PHA}^{-}$mutant and $0.5 \%$ sodium octanoate (Sigma) for mcl-PHA producers. These bacteria were cultured in a reciprocal shaker at $30{ }^{\circ} \mathrm{C}$ for 2 days to accumulate polyesters. The PHA-accumulated cells were diluted with water until the absorbance measured at $600 \mathrm{~nm}$ was 1.0 or less. One milliliter of diluted cells was collected by centrifugation and discarded the supernatant as clear as possible. Ten microliters of Nile red stock solution ( $1 \mathrm{mg} / \mathrm{ml}$ of Nile red in acetone) was slowly added to the cell pellet and mixed with the pipette tip. After incubating at room temperature for 5 min, the stained cells were dried with Speed $\operatorname{Vac}^{\circledR}$ 
(Savant) apparatus for $5 \mathrm{~min}$ to remove trace amounts of acetone, resuspended in $1 \mathrm{ml}$ of water, and subjected to scanning for maximal emission wavelength from 530 to $650 \mathrm{~nm}$ at a fixed excited wavelength of $488 \mathrm{~nm}$ (model F-4500, Hitachi, Tokyo, Japan) (Greenspan et al., 1985). To enhance the screening speed, bacteria could also be grown on mineral salt medium plates containing an appropriate carbon source instead of liquid culture. An approximately 2-mm-diameter colony was picked up with a toothpick, stained with $10 \mu \mathrm{l}$ of Nile red solution, and resuspended in $1 \mathrm{ml}$ of water. Wavelength scanning was performed as described above. Seven PHA-accumulating bacteria exhibited significant fluorescence maxima except for two $\mathrm{PHA}^{-}$mutants (Fig. 2). Furthermore, the fluorescence behaviour among PHA-accumulating bacteria could also be clearly classified into two groups, those with a fluorescence maxima around at $575 \mathrm{~nm}$ and those at $590 \mathrm{~nm}$ with $P$. glathei slightly shifted to $595 \mathrm{~nm}$ (Fig. 2, line 6). The bacteria strains of the $575 \mathrm{~nm}$ group, which included P. putida ATCC 12633, P. putida GPo1 ATCC 29347, and P. citronellolis ATCC 13674, are all mcl-PHAs producers according to previous reports (Timm and Steinbüchel, 1990). In addition, the strains of the 590 nm group, including $R$. eutropha H16 ATCC 17699,
C. acidovorans ATCC 15668, $P$. versutus, and $P$. glathei ATCC 29195, are all scl-PHAs producers as previous reports have described (Timm and Steinbüchel, 1990; Lee, 1996). To further confirm the PHA compositions and intracellular polyester content, these bacterial cells were collected and lyophilized (Brandl et al., 1988); approximately $10 \mathrm{mg}$ of lyophilized cells was subjected to methanolysis with a solution consisting of $0.15 \mathrm{ml} 98 \%$ sulfuric acid, $0.85 \mathrm{ml}$ methanol, $2 \mathrm{mg}$ benzoic acid as an internal standard, and 1 $\mathrm{ml}$ chloroform at $100{ }^{\circ} \mathrm{C}$ for $140 \mathrm{~min}$ to convert the constituents into methyl esters. After extracting the reaction mixture with $1 \mathrm{ml}$ water, the organic phase was dried over anhydrous sodium sulfate and analyzed with gas chromatography (GC) on a Shimadzu GC-17A equipped with a J\&W DB-5 capillary column $(30 \mathrm{~m} \times 0.25 \mathrm{~mm} ; 1 \mu \mathrm{m}$ film thickness $)$ and a flame-ionization detector operating in a split mode (split ratio, 1:50) with temperature programming (Ramsay et al., 1990). The PHA compositions of the $575 \mathrm{~nm}$ group strains and $590 \mathrm{~nm}$ group strains were mcl-PHAs and scl-PHAs, respectively, elucidated from the GC results (Table 1). The GC results strongly supported the idea that mcl-PHAs producers and sclPHAs producers can be differentiated based on fluorescence maxima at 575 and $590 \mathrm{~nm}$, respectively.

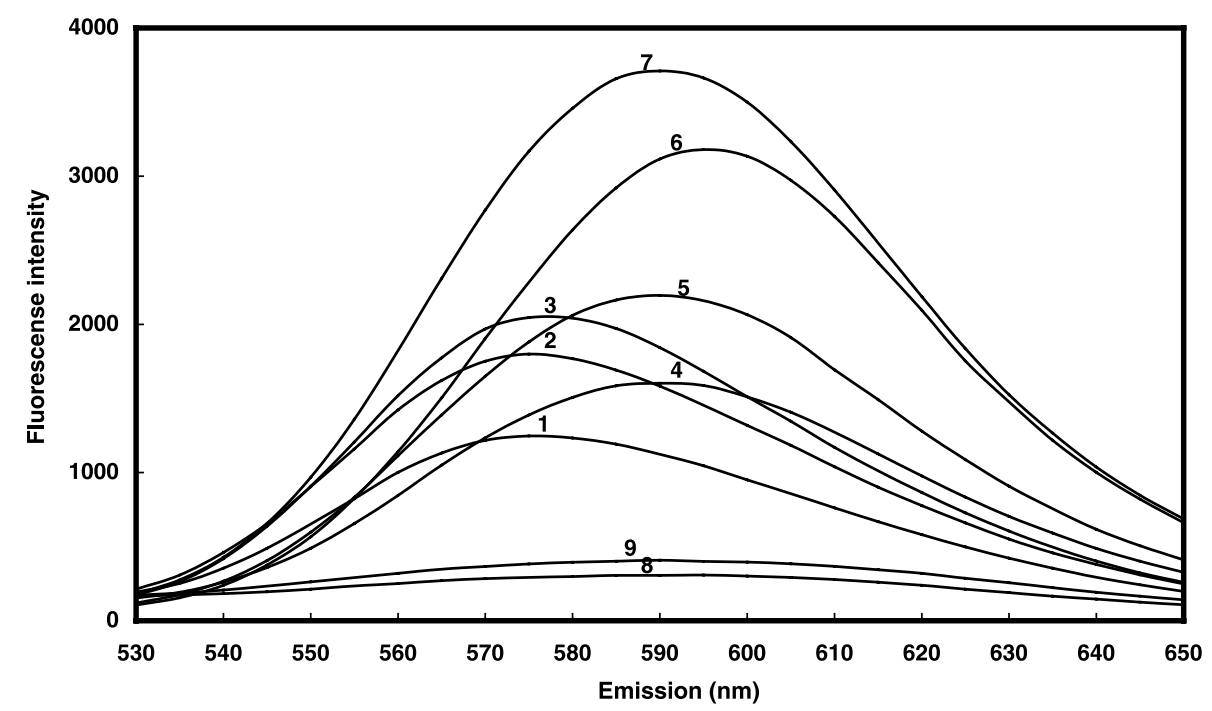

Fig. 2. Fluorescence spectra of bacteria grown on gluconate or octanoate as carbon sources and stained with Nile red. 1 , P. citronellolis ATCC13674; 2, P. putida ATCC 12633; 3, P. putida GPo1 ATCC 29347; 4, C. acidovorans ATCC 15668; 5, P. versutus; 6, P. glathei ATCC 29195; 7, R. eutropha H16 ATCC 17699; 8, R. eutropha PHB $^{-} 4$; 9, P. putida GPp104 PHA ${ }^{-}$. 
Table 1

Composition analysis of PHA accumulated from different bacterial strains

\begin{tabular}{|c|c|c|c|c|c|c|c|}
\hline \multirow[t]{2}{*}{$\begin{array}{l}\text { Strains } \\
\text { sto }\end{array}$} & \multirow{2}{*}{$\begin{array}{l}\text { Wavelength at } \\
\text { maximum }(\mathrm{nm})\end{array}$} & \multirow{2}{*}{$\begin{array}{l}\text { Carbon } \\
\text { source }\end{array}$} & \multirow{2}{*}{$\begin{array}{l}\text { PHA content } \\
(\%, w t / w t)\end{array}$} & \multicolumn{4}{|c|}{ Polymer composition (mol\%) } \\
\hline & & & & 3-HB & 3-HHx & $3-\mathrm{HO}$ & 3-HD \\
\hline Ralstonia eutropha $\mathrm{H} 16$ & 590 & gluconate & 83.5 & 100 & - & - & - \\
\hline Pseudomonas glathei & 595 & gluconate & 80.9 & 100 & - & - & - \\
\hline Comamonas acidovorans & 590 & gluconate & 31.8 & 100 & - & - & - \\
\hline Paracoccus versutus & 590 & gluconate & 46.9 & 100 & - & - & - \\
\hline Pseudomonas citronellolis & 575 & octanoate & 11.0 & 7.4 & 10.2 & 75.1 & 7.3 \\
\hline Pseudomonas putida GPo1 & 577 & octanoate & 36.5 & 3.2 & 10.1 & 82.9 & 3.8 \\
\hline Pseudomonas putida & 575 & octanoate & 22.6 & 3.5 & 5.7 & 88.0 & 2.8 \\
\hline Ralstonia eutropha $\mathrm{PHB}^{-} 4$ & - & gluconate & 0.6 & 100 & - & - & - \\
\hline Pseudomonas putida $\mathrm{PHA}^{-}$ & - & gluconate & - & - & - & - & - \\
\hline
\end{tabular}

-: not detected; 3-HB, 3-hydroxybutyrate; 3-HHx, 3-hydroxyhexanoate; 3-HO, 3-hydroxyoctanoate; 3-HD, 3-hydroxydecanoate.

Depending upon the relative hydrophobicity of the environment, the excitation and emission maxima of Nile red fluorescence can vary over a range of $60 \mathrm{~nm}$; the fluorescence colors range from golden yellow (emission wavelength, $>528 \mathrm{~nm}$ ) to deep red (emission wavelength, $>590 \mathrm{~nm}$ ) (Greenspan et al., 1985; Dutta et al., 1996). The scl-PHAs and mcl-PHAs show the chemical structure difference on the carbon side chain length and also reflect the inherent hydrophobicity, longer carbon side chain stronger hydrophobicity inherent. This may explain why Nile red staining elucidates different maximum emission wavelengths in scl-PHAs and mcl-PHAs. This approach was excellent for detecting PHAs; however, there was a disadvantage that occurred in differentiating between lipids and PHAs. To overcome this drawback, a genotype-detecting approach was required to further confirm Nile red staining results (Sheu et al., 2000).

It can be concluded that this method combining grown bacteria on a mineral salt medium plate is capable of being applied to rapid differentiating scland mcl-PHA producers isolated from environment.

\section{Acknowledgements}

We wish to thank professor G.-R. Her (Department of Chemistry, National Taiwan University, Taipei, Taiwan) for assistance in GC analysis and Professor A. Steinbüchel (Institut für Mikrobiologie der Westfälischen Wilhelms-Universität Münster, Münster, Germany) and Professor B. Witholt (Institute of Biotechnology, ETH Hönggerberg, Zürich, Switzer- land) for providing strains of Ralstonia eutropha $\mathrm{PHB}^{-} 4$ and Pseudomonas putida GPp104 $\mathrm{PHA}^{-}$, respectively.

\section{References}

Anderson, A.J., Dawes, E.A., 1990. Occurrence, metabolic role, and industrial uses of bacterial polyhydroxyalkanoates. Microbiol. Rev. 54, 450-472.

Brandl, H., Gross, R.A., Lenz, R.W., Fuller, R.C., 1988. Pseudomonas oleovorans as a source of poly( $\beta$-hydroxyalkanoates) for potential applications as biodegradable polyesters. Appl. Environ. Microbiol. 54, 1977-1982.

Degelau, A., Scheper, T., Bailey, J.E., Guske, C., 1995. Fluorometric measurement of poly- $\beta$ hydroxybutyrate in Alcaligenes eutrophus by flow cytometry and spectrofluorometry. Appl. Microbiol. Biotechnol. 42, 653-657.

Dutta, A.K., Kamada, K., Ohta, K., 1996. Spectroscopic studies of Nile red in organic solvents and polymers. J. Photochem. Photobiol. 93, 57-64.

Fouchet, P., Jan, S., Courtois, J., Courtois, B., Frelat, G., Barbotin, J.N., 1995. Quantitative single-cell detection of poly( $\beta$-hydroxybutyrate) accumulation in Rhizobium meliloti by flow cytometry. FEMS Microbiol. Lett. 126, 31-36.

Gorenflo, V., Steinbüchel, A., Marose, S., Rieseberg, M., Scheper, T., 1999. Quantification of bacterial polyhydroxyalkanoic acids by Nile red staining. Appl. Microbiol. Biotechnol. 51, 765-772.

Greenspan, P., Mayer, E.P., Fowler, S.D., 1985. Nile red: a selective fluorescent stain for intracellular lipid droplets. J. Cell Biol. 100, 965-973.

Kranz, R.G., Gabbert, K.K., Madigan, M.T., 1997. Positive selection systems for discovery of novel polyester biosynthesis genes based on fatty acid detoxification. Appl. Environ. Microbiol. 63, 3010-3013.

Lee, S.Y., 1996. Bacterial polyhydroxyalkanoates. Biotechnol. Bioeng. 49, 1-14.

Ostle, A.G., Holt, J.G., 1982. Nile blue A as a fluorescent stain for poly- $\beta$-hydroxybutyrate. Appl. Environ. Microbiol. 44, $238-241$. 
Poirier, Y., Nawrath, C., Somerville, C., 1995. Production of polyhydroxyalkanoates, a family of biodegradable plastics and elastomers, in bacteria and plants. Bio/Technology 13, 142-150.

Ramsay, B.A., Lomaliza, K., Chavarie, C., Dubé, B., Bataille, P., Ramsay, J.A., 1990. Production of poly-( $\beta$-hydroxybutyricco- $\beta$-hydroxyvaleric) acids. Appl. Environ. Microbiol. 56, 2093-2098.

Sheu, D.-S., Wang, Y.-T., Lee, C.-Y., 2000. Rapid detection of polyhydroxyalkanoate-accumulating bacteria isolated from the environment by colony PCR. Microbiology 146, 2019-2025.

Spiekermann, P., Rehm, B.H.A., Kalscheuer, R., Baumeister, D., Sheinbüchel, A., 1999. A sensitive, viable-colony staining me- thod using Nile red for direct screening of bacteria that accumulate polyhydroxyalkanoic acids and other lipid storage compounds. Arch. Microbiol. 171, 73-80.

Timm, A., Steinbüchel, A., 1990. Formation of polyesters consisting of medium-chain-length 3-hydroxyalkanoic acids from gluconate by Pseudomonas aeruginosa and other fluorescent Pseudomonads. Appl. Environ. Microbiol. 56, 3360-3367.

van Beilen, J.B., Panke, S., Lucchini, S., Franchini, A.G., Röthlisberger, M., Witholt, B., 2001. Analysis of Pseudomonas putida alkane-degradation gene clusters and flanking insertion sequences: evolution and regulation of the alk genes. Microbiology 147, 1621-1630. 